\title{
Developing Multicultural Self-awareness Through a Transformative Learning Experience
}

\author{
Cynthia Bezard ${ }^{\mathrm{a}}$, Sara A. Shaw ${ }^{\mathrm{b}}$ \\ ${ }^{a}$ Basic Academy of International Studies; ${ }^{b}$ University of Nevada, Las Vegas
}

\begin{abstract}
The purpose of this qualitative case study was to explore the ways that a change in perspective can create a better unders tanding of cultural identity. This study addressed:(1) How does a self-awareness transformative learning experience develop critical cultural competence in career and technical education instructors? (2) How does the practice of critical reflection construct career and technical education instructors' ability to develop self-awareness of critical cultural competence?(3) How does involvement in critical discourse construct career and technical education ins tructors' ability to develop self-awareness of critical cultural competence? A three-phase professional development experience rooted in multicultural education provided key elements of transformative learning.
\end{abstract}

Keywords: career and technical education, transformative learning theory, multicultural education, identity development, career development

"Becoming a teacher means (1) transforming an identity, (2) adapting personal understanding and ideals to institutional realities, and (3) deciding how to express one's self in classroomactivity” (Rodgers \& Scott, 2008, p. 732).

\section{Introduction}

Historically, Career and Technical Education (CTE) instructors have been responsible for preparing their students to enter and succeed in the workforce. Expectations for CTE instructors have drastically changed since the initial introduction of vocational education. The challenges that they face in the twentyfirst century include accommodating career development needs and future employment opportunities; meeting higher academic achievement standards in math, sciences, communication, and technology; preparing students to demonstrate higher order skills in reasoning, problem-solving, and collaborative work; being held to a demand of greater accountability; ongoing curriculum revisions; and serving a more diverse student population (McCaslin \& Parks, 2002).

CTE instructors "have always faced the challenge of educating students with diverse needs and abilities" (Reese, 2005, p. 15) and are at the helm of preparing future high-growth industry employees. This creates a crucial need for multicultural-educated instructors. Multicultural education recognizes different points of views, provides ethnic minorities with a sense of belonging, and reduces stereotypes and prejudices that can hinder student achievement (Gay, 2010; Banks, 2004).

\section{Identifying the Problem}

The typical CTE instructor comes frombusiness and industry where hands-on, occupational work experience makes them an expert in their field (Ruhland \& Bremer, 2002). While rich in occupational experience, many CTE instructors lack traditional teacher preparation experience (McCaslin \& Parks, 2002). This may contribute to a teaching environment in which the CTE instructor is less able to respond to the needs of a diverse student population than those individuals with a traditional teacher preparation background. The gaps presented by this nontraditional entry into the educational field can be addressed by additional learning opportunities for the CTE instructor.

The anatomy of today's secondary classroom has changed and is expected to continue changing (Hoy \& Hoy, 2006). By the year 2020, it has been projected that 66 percent of the students in our classrooms will be children of color. CTE instructors will face many challenges including working with students that have different racial, cultural and ethnic backgrounds from their own (Hoy \& Hoy, 2006). With this increase in diverse student population it has become a priority to help instructors acquire the attitudes, knowledge, skills, and dispositions that are needed to be effective in the diverse classroom (Cooper, He, \& Levin, 2011; Chou, 2007; 
Gay, 2010; Grant, Elsbree, \& Fondrie, 2004; LadsonBillings, 2001).

Previous studies indicate a relationship between instructors' attitudes, behaviors and the achievement of students (Brophy \& Good, 1984). Questions to ponder may be: If a CTE instructor's race, ethnicity, social class, or culture differs from the students that they are teaching, how are they to understand and effectively educate the racially, ethnically, and culturally diverse CTE student? How can our CTE instructors appropriately deal with stereotypes of racially, ethnically, and culturally diverse students as they prepare them to enter the workforce? How can these CTE instructors ensure each student is valued and treated respectfully in their class room?

\section{Background of the Problem}

To fit the needs of the twenty-first century, the Ass ociation for Career and Technical Education (ACTE) created a report of how an updated education system should look(ACTE, 2006). The report proposed that CTE should be modified to do the following:

(a) support students in the acquisition of rigorous core knowledge, skills, habits and attitudes needed for success in postsecondary education and the highskilled workplace, (b) engage students in specific career-related learning experiences that equip them to make well-informed decisions about further education and training and employment opportunities, and (c) prepare students who may choose to enter the workforce directly after high school with levels of skills and knowledge in a particular career area that will be valued in the marketplace (Stone, 2010, p. 1).

To improve student achievement in the twenty-first century, a beyond-knowledge understanding of diversity by CTE instructors is necessary (Cooper et al., 2011; Darling-Hammond \& Bransford, 2007). Cooper and colleagues define this beyond-knowledge understanding of diversity as critical cultural competence. Critical cultural competence is based on "critical reflection of self, students, families, and communities” (p. xv).

For this research study, the American Evaluation Ass ociation (AEA) definition of cultural competence was used:

Cultural competence is not a state at which one arrives; rather, it is a process of learning, unlearning, and relearning. It is a sensibility cultivated throughout a lifetime. Cultural Competence requires awareness of self, reflection on one's own cultural position, awareness of other's positions, and the ability to interact genuinely and respectfully with others. (AEA, 2011, p. 3)

Research has indicated culturally competent educators can improve the academic and occupational success of diverse students (Gay, 2010; Grant et al., 2004; Ladson-Billings, 2001. With a foundational understanding of critical cultural competence, educators can create fair and impartial classrooms that nurture academic achievement (Cooper et al., 2011). Development of critical cultural competence can be best achieved through ongoing learning opportunities (Cooper et al., 2011). Learning opportunities rooted in the transformative learning theory complements the definition of cultural competence used in this research study.

\section{Purpose of the Study}

To be successful in the classroom for all students, CTE instructors need to foster personal growth and development as well as focusing their attention on developing students (Cranton, 1996; Zeichner \& Liston, 1996). Research has indicated culturally competent educators can improve the academic and occupational success of diverse students (Gay, 2010; Grant et al., 2004; Lads on-Billings, 2001) However, little attention has been given to how development of multicultural selfawareness may influence CTE instructors' development of critical cultural competence. The purpose of this research study was to examine transformative learning experiences of CTE instructors, specifically focusing on the development of multicultural self-awareness. According to Mezirow (1991), adult educators have a responsibility to help their students (i.e., CTE instructors) become more "imaginative, intuitive, and critically reflective of assumptions; to become more rational through effective participation in critical discourse; and to acquire meaning perspectives that are more inclusive, integrative, discriminating, and open to alternative points of view" (p. 224).

\section{Brief Review of Literature and Theoretical Framework}

As educators, we look to multicultural education to provide a path of creating an instructional practice that provides equal opportunities for all students in the classroom. A significant purpose of multicultural education is reduction of stereotyping and prejudice (Banks, 1981), which is necessary for students to develop the knowledge, attitudes, and skills necessary to participate in the workforce and in society. Transformative learning theory guided this research study. Additionally, Erikson's theory of identity development was used to demonstrate the importance of identity and vocational development during adolescence.

Transformative Learning Theory. Transformative learning can be described as the action of closely inspecting one's beliefs, values, and assumptions in order to gain understanding and develop new knowledge (Mezirow, 1990, 2000). Changing the way one looks at current and past events can spark the beginning of personal and social growth that then materializes into transformation (Mezirow, 1990). 
For the past 25 years, transformative learning theory has been a growing field in adult education (Taylor, 2007). Transformative learning theory is uniquely adult, abstract and idealized, and grounded in the nature of human communication (Taylor, 2007 It focuses on the ability of the learner to interpret, verify, and then redefine their past experiences to change their current opinions, perspectives, and responses (Imel, 1998; Mezirow, 1996; Taylor, 2007). Transformative learning offers a framework through which we can identify the essence and degree of a desired perspective transformation (Mezirow, 1990). Transformative learning theory is a well-liked adult learning theory that faculty in higher education can use to design and promote experiences in their classrooms that may challenge students to analyze their current perspectives and develop different perspectives that may guide new ways of acting (Mezirow, 1996). Adult educators can design learning experiences that seek to transform their students' knowledge, skills, and dispositions. Transformative learning theory offers a credible lens through which this process can be viewed.

Erikson's Identity Development Theory. In the field of psychology, Erik Eriks on is considered a foundational theorist. Eriks on's theory is presented in eight stages, beginning with infancy and ending with mature age. The fifth stage of Eriks on's theory has to do with identity development. Eriks on (1963) defined identity as "the ability to experience one's self as something that has continuity and sameness and to act accordingly" (p.42). Eriks on was instrumental in presenting vocational development as an essential and critical part of adolescent development(Vondracek, Schulenberg, Skorikov, Gillespie, \& Wahlheim, 1995). This is important to this research study as high school CTE instructors are working with students during adolescence.
Multicultural Education. Multicultural education is a way of teaching and learning founded on democratic values that create cultural oneness (Bennett, 1998). The major goal of multicultural education is to recreate the practices of educational institutions so that all students have an equal opportunity for achieving academic excellence (Banks, 2004). It is an instructional and teaching model that fuses the "history, cultural traditions, social norms, life experiences, and learned contributions that members of nondominant groups have made to all aspects of society" (Clark, 2013, p. 1502). Multicultural theorists are very interested in the interaction between race, class, and gender and how those interactions impact education (Banks, 1998; Grant \& Sleeter, 1988). The theories and practices of multicultural education manifest in the promotion of social change.

Critical Cultural Competence. Culture can be described as the way humans act or interact and may include a combination of thought, communication, actions, customs, beliefs, and values (Catoe, 2010). Competence is possessing the required skill, knowledge, qualification, or capacity to function within a certain circumstance (Competence n.d.). The development of critical cultural competence is when behaviors, attitudes, and policies come together in a system, agency, or profession and enable that system, agency, or profession to effectively participate in cross-cultural situations (Cross, Bazron, Dennis, \& Isaacs, 1989). The five ess entials elements of a culturally competent system are "(1) valuing diversity, (2) having the capacity for cultural self assessment, (3) being conscious of the dynamics inherent when cultures interact, (4) institutionalizing cultural knowledge, and (5) creating new ways to deliver an understanding of the differences between and within cultures” (Cross, et al., 1989).

Table 1. Mezirow's Ten Phases of Transformative Learning

\begin{tabular}{cl}
\hline Step & Transforming Dimension \\
\hline 1 & A dis orienting dilemma \\
2 & A self-examination with feelings of fear, anger, guilt, or shame \\
4 & A critical ass essment of as sumptions \\
5 & Recognition that one's dis content and the process of transformation are shared \\
6 & Planning a course of action \\
7 & Acquiring knowledge and skills for implementing one's plan \\
8 & Provisionally trying new roles \\
9 & Building competence and self-confidence in new roles and relationships \\
10 & A reintegration into one's life on the basis of conditions dictated by one's perspective
\end{tabular}

Adapted from “Transforming Dimensions of Adult Learning” by Jack Mezirow, 1991, Copyright 1991 by John Wiley and Sons. 
Journal of Research in Technical Careers

Table 2. Eriks on's Theory of Identity Development

\begin{tabular}{clll}
\hline Stage & Period & Crisis & Positive Resolution \\
\hline 1 & First year & Trust vs. mistrust & Sense of security \\
3 & Second year & Autonomy vs. shame/doubt & Sense of independence \\
4 & $3-5$ years & Initiative vs. guilt & $\begin{array}{l}\text { Balance between spontaneity and } \\
\text { restraint }\end{array}$ \\
5 & 6 years to puberty & Industry vs. inferiority & Sense of self-confidence \\
6 & Adolescence & Identity vs. role confusion & Unified sense of self \\
7 & Young adulthood & Intimacy vs. is olation & Form close pers onal relationships \\
8 & Middle adulthood & Generativity vs. stagnation & Promote well being of others \\
& Late adulthood & Integrity vs. despair & Sense of satisfaction with life well \\
\hline
\end{tabular}

Adapted from “Identity and the Life Cycle” by Erik Eriks on, 1959, Psychological Issues, 1, p. 22. Copyright 1959 by Norton.

While theorists have presented different approaches and models of multicultural education (Banks, 1998; Nieto \& Bode, 2008; Grant \& Sleeter, 2006), they all stress the importance for educators to: (a) participate in critical self-reflection about their assumptions and cultural beliefs, (b) cultivate a rich and meaningful understanding of student diversity and assets, and (c) look upon the funds of knowledge brought with the students from their community culture and heritage as pertinent to their educational path (Cooper et al., 2011). Cooper and colleagues (2011) combined these concepts to develop a foundation for developing critical cultural competence. The goal for developing or enhancing educators' critical cultural competence is to "impact instructional practices and to promote the achievement of students, especially those who are culturally, ethnically, and linguistically diverse" (Cooper et al., 2011, p. 6) (Figure 1).

Self-awareness. To acquire cultural knowledge of self is part of developing culturally appropriate pedagogical techniques in the classroom (Spindler \& Spindler, 1993). To further expound on development of self knowledge, Howard (1999) states that success comes with personal reflection during transformation. Howard (1999) suggested that by understanding our past and how it has shaped certain racial myths, we can rectify our thoughts, emotions, and behaviors as they relate to human diversity.

\section{Research Questions}

This research study explored how developing multicultural self-awareness through a transformative learning experience can impact CTE instructors' approaches in the classroom. The primary question that guided this research study was: How does a selfawareness transformative learning experience develop critical cultural competence in CTE instructors? Two ancillary questions were also considered: 1) How does the practice of critical reflection construct CTE instructors' ability to develop self-awareness of critical cultural competence? 2) How does involvement in critical discourse construct CTE instructors' ability to develop self-awareness of criticalcultural competence?

\section{Approach to the Study}

The research chosen for this study was qualitative inquiry as it creates a situation where the researcher develops a meaningful and rich understanding of a participant's experience (Green \& Thorogood, 2014). Empirically, qualitative research methods have been predominant in the field of transformative learning as Mezirow (2009) stated "to understand communicative learning, qualitative research methods are often more appropriate” (p. 59). For the field of transformative learning theory employment of the qualitative method is necessary to "explore the problem, honor the voices of participants, map the complexity of the situation, and convey multiple perspectives of participants" (Creswell \& Plano Clark, 2011, p.7). Furthermore, how much the phenomenon has been studied influences the research method that is chosen (Merriam, 1988).

More specifically, this was a qualitative, bounded, case study (Creswell, 2013; Merriam, 1988) that attempted to add to the current knowledge base on CTE instructors' development of multicultural self-awareness through transformative learning experiences. A case study is chosen when (a) "how" or "why" questions are being posed, (b) the investigator has little control over 


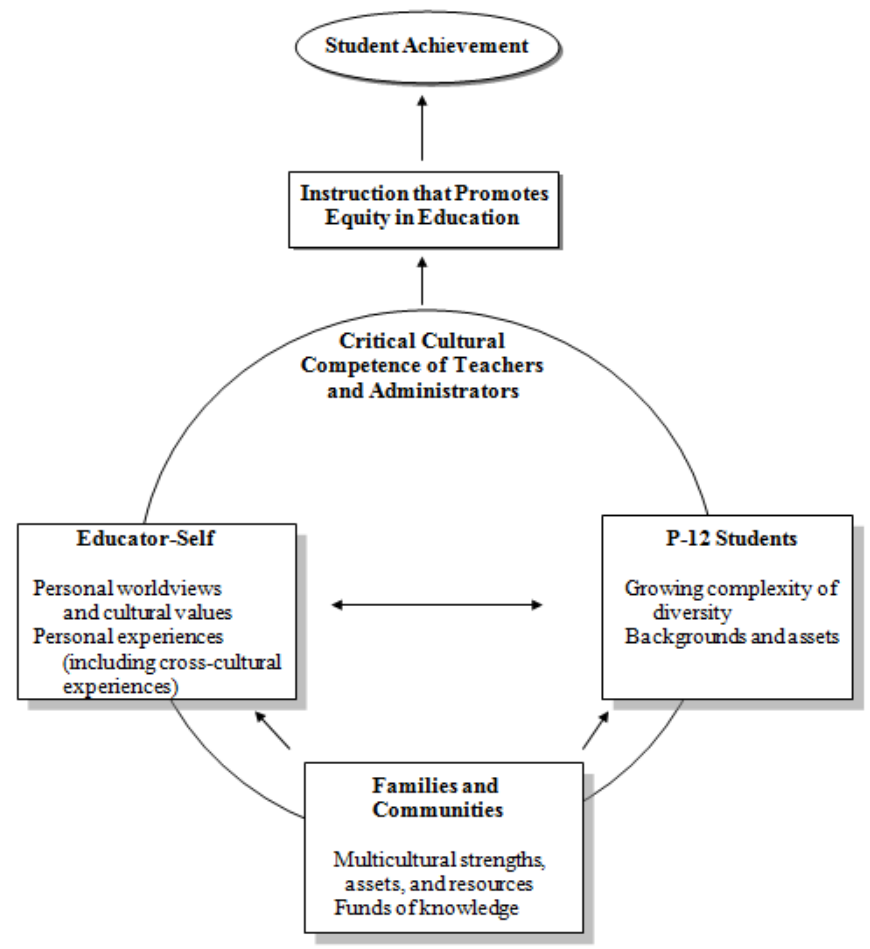

Figure 1. Goal of Teacher Critical Competence. Adapted from “Teacher Critical Competence” by Cooper et al., 2011, Developing Critical Cultural Competence, p. 7. Copyright 2011 by Corwin. Note: this research study focused on educatorself development.

events, and (c) the focus is on a contemporary phenomenon with a real-life context" (Creswell, 2013, p.2). Qualitative studies are exploratory and enable the researcher to study participants in natural settings (Creswell, 2013; Denzin \& Lincoln, 2005). The researcher has an opportunity to access in-depth information and to uncover pertinent knowledge that may not emerge if using controlled methods. This research study is bounded as the boundaries are the activities that the participants are involved in during a specific time and place (Creswell, 2013).

As an attempt to understand human behavior, the research used the interpretative approach. Green and Thorogood (2014), state that an aspect to understanding human behavior is being able to view people's interpretation of their world. The philos ophical approach used in this research is that of phenomenology (Creswell, 2013; Merriam, 1988). This research attempted to report the common meaning for several individuals as they experience the phenomena of a transformative learning experience (Creswell, 2013; Merriam, 1988).

\section{Methodology}

This research study tookplace in a public university in the southwest region of the United States. Institutional Review Board (IRB) approval was obtained to conduct this research. This qualitative study involved three phases. Phase I and Phase II were designed to ignite the transformative learning process. Phase III consisted of face-to-face interviews with research participants.

Participants and Rationale for Participant Sample. Convenience and purposeful sampling was used (Creswell, 2013). As this study gained access to participants froma specific geographic area convenience sampling is employed (Merriam, 1998). This study included CTE instructors who were enrolled in an accredited public postsecondary university in the southwest region of the United States. This setting is an accredited postsecondary institution where business and industry licensed CTE instructors can earn the mandatory 12 semester credit hours towards their license.

The selection of the instructors was based on their willingness to participate in the study and the ability of instructors to meet with the researcher and attend individual and group sessions. Since the focus of this study was on transformative learning experiences of business and industry CTE instructors, instructors currently attending courses to maintain their business and industry license at a public university qualified to participate in this research study. This straightforward selection of participants who are likely to provide appropriate and useful data (Green \& Thorogood, 2014) 
follows the method of purposeful sampling in qualitative research (Creswell, 2013; Coyne,1997). Res earch sample selection is important in qualitative research as it affects the quality of the research (Coyne, 1997; Merriam, 1998). According to Patton (1990), "the...logic and power of purposeful sampling lies in selecting information-rich cases for study in depth” (p. 169). Patton (1990) goes on to state that "qualitative inquiry typically focuses in depth on relatively small samples, even single cases, selected purposefully" (p. 169).

A questionnaire was used to gather information about participant demographics. Participant names have been changed (Table 3).

Role of Researcher. The first author on this paper was the sole researcher in this research study, the custodian of all data, and the data analyzer. Responsibilities included developing and implementing all aspects of the research study, including developingthe transformative learning experience, participant recruitment and consenting, creating all interview questions, conducting all the participant interviews, and transcribing the interviews. To ensure objectivity and validity of data analys is, the assis tance of an experienced research faculty member through an intercoder agreement was used.

Phase I. Phase I consisted of the introduction to research; collection of demographic and background information; identification of student, school, and curriculum information; past participation in diversity training; completion of Harvard's Implicit Association Test; and engagement in self-reflection through formulated questions. This phase began the ten-phase transformation process Mezirow (1995) articulates in the transformative learning theory. The first phase is a dis orienting dilemma. This dilemma represents the first of three key themes of Mezirow's transformative learning theory experience - participants have an experience that does not fit with their pre-existing meaning structure, causing a disorienting dilemma. As long as our experiences match our current way of thinking we tend to not participate in transformative learning (Mezirow, 1995). In this phase of the study, students completed the Implicit Association Test (IAT). This phase also addressed aspects of the second of the theory's themes critical reflection. After experiencing a disorienting dilemma through critical reflection there is a selfexamination with feelings of guilt or shame and a critical assessment of epistemic, sociocultural, or psychic assumptions (Mezirow, 1991)

Implicit association test. The Implicit Association Test (IAT) is an instrument used to investigate thoughts and feelings that people may be unwilling or unable to report (Project Implicit, 2011). IAT was chosen because it is a valid instrument for measuring hidden racial and gender biases. Res earch has shown that those who show a strong IAT effect are more likely to demonstrate overt racist behavior (Nosek, Greenwald, \& Banji, 2007).

Phase II. Phase II consisted of a PowerPoint presentation on developing critical cultural competence, activities that began to help all participants explore personal characteristics and beliefs, a follow-up group meeting that included group discussion questions, and questions fromKember et al. (2000) were used to assess critical reflection. This helped the participants focus on the first insights required for developing instructors' critical cultural competency: understanding thems elves. This phase addressed aspects of the second of the theory's themes, critical reflection, as well as the third of the theory's themes, rational dis course (Mezirow, 1991). The activities that the participants complete begin the steps of exploring pers onal characteris tics and beliefs. Answering the reflection questions facilitates self-examination and critical assessment that are aspects of the second of the theory's themes. As there is a group discussion after the activities, the third theme, rational discourse, provides opportunity for exploring with others the newly discovered misunderstanding between as sumptions and reality, specifically, grasping one's discontent, sharing the process of transformation, and understanding that others have negotiated a similar change. This exchange allows for exploration of options for new roles, relationships, and actions with others.

PowerPoint presentation. This presentation introduced the participants to the definition of cultural competence used for research study, a foundational understanding about diversity through the lens of Milner's five conceptual repertoires of diversity, including the steps necessary to go beyond knowledge of diversity, and Edward T. Hall's iceberg analogy of culture.

Table 3. Participant Demographics

\begin{tabular}{cccc}
\hline Participant & Age & Race/Ethnicity & Gender \\
\hline Jim & 34 & White & Male \\
Lauren & 54 & European/White & Female \\
Sarah & 34 & Korean/Asian & Female \\
Samuel & 54 & Black & Male \\
Julianne & 29 & White/Irish & Female \\
Alexis & 55 & Caucasian & Female \\
Kelly & 33 & Asian & Female \\
Scott & 50 & Caucasian/White & Male \\
\hline
\end{tabular}


Autobiography activity. Autobiographies provide a way for the instructor to use facts as they begin to investigate themselves (Cooper et al., 2011). The objective of this activity was to provideparticipants with an opportunity to share how they perceive thems elves in relation to aspects of cultural beings, and to explore their own cultural assumptions (Cooper, et al., 2011).

Bio-poem. Bio-poems are a simple and effective way for the participants to express how they want others tosee them as they choose the words that describe thems elves, their interests, and their lives (Cooper et al., 2011). The objective of this activity was to provideparticipants with an opportunity to express what they want others to know about themselves (Cooper, et. al, 2011).

Privilege walk. A privilege walk gives the participants an opportunity to discover diversity within themselves and to uncover preconceived notions and beliefs about others (Cooper et al., 2011). The objective of this activity was to provide participants with an opportunity to understand the intricacies of privilege (Cooper et al., 2011). Participation in the privilege walk reveals how certain perceptions associated with race, ethnicity, class, gender, ability, and religion are forms of privilege for some and not for others (Cooper et al., 2011).

Group discussion. Cranton (1994) states that educators need to participate in conversation with others in order to be exposed to different views and to decide if those views are logical. Furthermore, Mezirow (2000) suggests that to foster effective rational dis course, a safe and accepting environment that is free from judgment is necessary in order to reduce and ease the possible psychological and emotional distress the participants may encounter. As the researcher facilitated the transformative learning experience, every attempt to create the best conditions in which to nurture discourse was made. As the researcher facilitated the group discussion, use of a note-taker was used to ensure accurate dictation of the dialogue.

Phase III. Phase III consisted of individual, face-toface, semi-structured interviews. Interview questions were designed to assess information about how selfawareness through a transformative learning experience changed their perceptions. This final interview attempted to take a rich and meaningful look at the possible transformative learning experience of the participant. Phase I and Phase II provided opportunities for disorienting dilemmas which is the first of the theory's phases. These dilemmas or a-ha moments can be all at once or gradual over time and display a disconnect between our understanding and reality.

\section{Data Analysis and Interpretation}

From the collected data an in-depth understanding was gained of how self-awareness can be obtained through transformative learning experiences. During the analysis stage, the researcher reviewed field notes and face-to-face interviews to determine the emergence of themes. More specifically, the researcher sought indigenous themes that characterized the experience of the research participants.

Data analysis included analyzing interviews, document analysis, and participation observations. According to Cres well(2013), there are six steps to take when analyzing the qualitative data: organize and prepare (transcribe), read through all the transcribed data to understand the overall meaning, code and label the data in chunks, organize the chunks of codes or labels into smaller numbers of categories and themes, identify the themes found in the interview data, and make interpretation or meaning of the data.

In order to ensure a rich, robust, comprehensive, and well-developed study it is recommended to use multiple data sources (Denzin, 1978; Patton, 1999). Triangulation involves using multiple data sources to produces understanding. The types of triangulation used in this research study are triangulation of sources (companing people with different points of view), analyst triangulation (using multiple analysts to review findings), and theory/perspective triangulation (using multiple theoretical perspectives to examine and interpret the data) (Denzin, 1978; Patton, 1999). The use of multiple data sources also serves to enhance each data source as it provides the data collected in one area to shed light on data collected in another area (Creswell, 2013; Merriam, 1988).

\section{Findings and Implications}

Important to the field of CTE are the major findings concerning the primary research question: How does a self-awareness transformative learning experience develop critical cultural competence in CTE instructors? All eight of the research participants experienced at least one of the ten phases of transformative learning (see Table 1) as it pertains to development of multicultural self-awareness and critical cultural competence. There were also findings that aligned with advanced transformative learning as two of the participants made changes to their approaches in the classroom based on this transformative learning experience. Examples included changes in communication with students, changed graphic representation of students, and awareness of student names. Since the professional development aspect of this research study employed critical thinking, personal reflection, critical discourse, and mentoring it is not an unexpected finding that some levels of trans formative learning transpired (King, 2005; Taylor, 1998). Since transformative learning is a uniquely individual experience, it was not an unexpected finding that not all participants responded the same to the learning experience (King, 2005; Taylor, 1998).

The first ancillary question was: How does the practice of critical reflection construct CTE instructors' 
ability to develop self-awareness of critical cultural competence? Findings indicated underdeveloped personal reflection skills in the research participants. Personal self-reflection is the process that enables the adult learner to question the accuracy of as sumptions and beliefs that are rooted in past experiences. For adult learners to have the ability to reflect on one's own practice, to grow, and change professionally is to be an effective practitioner (Cranton, 1996; Mezirow, 1991; Sparks, 1999). In analyzing the personal reflections of the research participants, answers to the reflection questions lacked depth and failed to delve into particants' practice, as participants answered questions with "yes” and "no" responses.

The second ancillary question was: How does involvement in critical discourse construct CTE instructors' ability to develop self-awareness of critical cultural competence? Findings indicated that CTE instructors were able to engage in critical dis course when provided the correct environment. Res earch participants shared: "People became more open and more acceptable and less judgmental after a while," "It was a safe environment where we trusted each other," and "there was an intimacy in the classroom provided by the res earcher." To foster effective rational dis course, a safe and accepting environment that is free from judgment is necessary in order to reduce and ease the possible psychological and emotional distress the participants may encounter (Mezirow, 2000). It was the role of the research to provide the correct environment to foster positive critical discours e for the res earch participants.

The findings of this research study support the prioritization to help CTE instructors acquire the attitudes, knowledge, skills, and dispositions that are needed to be effective in today's classroom (Cooper et al., 2011; Chou, 2007; Gay, 2010; Grant et al., 2004; Ladson-Billings, 2001). To be effective in today's classroom, CTE instructors need time and opportunities to develop, master, and reflect on effective ways of working with their students. Professional development for educators teaching future CTE instructors may be necessary to develop the attitudes, knowledge, skills, and dispositions to guide CTE instructors to be more effective in today's diverse classroom.

According to Judith Warren Little (1994), a model of instructor professional development that is primarily focused on expanding well-defined and skillful classroom practice is not adequate to the demanding vision of today's teaching and schooling. Instructors in the twenty-first century needs to have the skills that serve diverse learners effectively (Cooper et al., 2011; DarlingHammond, 2006). Milner (2010) states that prepaning today's instructors for diversity, equity, and social justice are perhaps the most demanding and taxing job facing the field of higher education.

This research study was designed as professional development focusing on developing self-awareness through a transformative learning experience. The findings imply that through a transformative learning experience research participants developed a greater understanding of the perceptions they hold, the values they take to the classroom, and the beliefs they have about career and technical education. Since adult learning is considered a lifelong journey, continuing to create and provide learning opportunities that focus on developing critical cultural competence in CTE instructors will help nurture and support student achievement.

\section{Recommendations for Further Research}

While this study did not examine every aspect of developing multicultural self-awareness through transformative learning experiences, the results did provide a basis for future research on thetopic.

Additional studies that address continued development of critical cultural competence are needed and suggested here.

A longitudinal qualitative research study could be conducted to determine if after the initial transformative learning experience, research participants continued the development of professional critical cultural competence.

A longitudinal qualitative study spanning at least one year and designed as a three-phase continuum professional development on critical cultural competence could be conducted to determine if ongoing professional development in critical cultural competence is beneficial to CTE instructors by building on prior learning experiences.

Further examination of the development and use of pers onal reflection skills of CTE instructors could also be considered. An exploratory sequential mixed methods research study (Creswell \& Plano Clark, 2011) designed to examine the development of reflection skills in CTE instructors could be conducted in order to determine how many CTE instructors use personal reflection, whether there is a need to develop personal reflection skills, and the best way to develop those skills.

A replication of this study that includes CTE instructors beyond their first year of teaching could be developed. As a large portion of CTE instructors do not enter the classroom through the traditional instructor preparation programs the first year in the classroom is spent learning day-to-day operations such as methods, classroom management, and administrative duties. Attitudes, knowledge, and skills develop and change beyond the first year of teaching that could affect the results of the research study.

Lastly, any of these studies could be applied to other instructors who have entered the classroom via an alternative route to licensing. These research studies would address the importance of multicultural education for all of today's instructors - Alternative Route to Licensure, Teach For America, and even substitute teachers. 


\section{Conclusion}

Transformative learning can be described as the action of closely inspecting one's beliefs, values, and assumptions in order to gain understanding and develop new knowledge (Mezirow, 1990, 2000). Changing the way one looks at current and past events can spark the beginning of personal and social growth, which then develops into a transformation.

Overall, analysis of the descriptive data, personal reflections, group dialog, and face-to face interviews found that seven of the research participants in this study had begun to experience phases one through five of Mezirow's transformative learning. Findings also showed that two research participants experienced phases five and six of Mezirow's transformative learning. Analysis of the data indicated the key factors of transformative learning (critical thinking skills, pers onal self-reflection, classroom discussions and dialogues, and mentoring) were utilized to produce the transformative learning experience. However, there were findings that indicated pers onal reflection skills were underdeveloped. This lack of personal reflection skills may halt the ability to reflect on one's own practice, to grow, and change professionally.

Beyond delivering education, the focus of this research study was to shape change in self-understanding and basic "ways of knowing” (King, 2005, p. 2). Creating an environment for CTE instructors to understand themselves and their world in new ways can open the door for new perceptions - perceptions that lead to cultural competence. An introduction to the key elements of transformative learning promotes shifts in understanding (King, 2005). Research participants were able to question their previously held perceptions, beliefs, and values in order to develop the attitudes, knowledge, skills, and dispositions to be successful in their diverse classrooms.

\section{References}

Ass ociation for Career and Technical Education. (2006). Reinventing the American high school:

Strengthening a new vision for the American high school through the experiences and resources of Career and Technical Education. Retrieved from https://www.acteonline.org/uploadedFiles/Assets_a nd_Documents/Global/files/Reinventing_American _High_School.pdf

American Evaluation Association. (2011). Public statement on cultural competence in evaluation. Retrieved from www.eval.org

Banks, J. A. (1981). The multiethnic curriculum: Goals and characteristics. In P. Dev (Ed.), Multicultural education: What do we need to know to better meet our student's needs?(pp. 105-116). Lafayette, IN: Purdue University.
Banks, J. A. (1998). The lives and values of researchers: Implications for educating citizens in a multicultural society. Educational Researcher, 27(7), 4-17.

Banks, J. A. (2004). Multicultural education: Historical development, dimensions, and practice. In J.A. Banks \& C. A.M. Banks (Eds.). Handbook of research on multicultural education (2nd ed., pp. 329). San Francisco, CA: Joss ey-Bass.

Bennett, M. J. (1998). Intercultural communication: A current perspective. In M. J. Bennett (Ed.), Basic concepts ofintercultural communication: Selected readings (pp.1-20). Yarmouth, ME: Intercultural Press.

Brookfield, S. D. (1986). Understanding and facilitating adult learning. San Francis co, CA: Jossey-Bass.

Brophy, J., \& Good, T. L. (1984). Teacher behavior and student achievement. Occasional paper no. 73. Retrieved from http://files.eric.ed.gov/fulltext/ED251422.pdf

Catoe, S. D. L. (2010). Examining social studies teachers' cultural competence in a South Carolina suburban public high school: Implications for diversity training (Doctoral dissertation). Retrieved from ProQuest Dissertations \& Theses Global. (Order No. 3402757)

Chou, H. (2007). Multicultural teacher education: Toward a culturally responsible pedagogy. Essays in Education, 21(1), 139-162.

Clark, C. (2013). Multicultural education. In C. Cortés (Eds.), Multicultural America (pp. 1502-1505). Thous and Oaks, CA: Sage Publications, Inc.

Cooper, J., He, Y., \& Levin, B. (2011). Developing critical cultural competence: A guide for 21st century educators. Thousand Oaks, CA: Sage Publications, Inc.

Competence [Def. 1.]. (n.d.). In Dictionary Online. Retrieved February 22, 2015 from http://dictionary.reference.com/browse/competence

Coyne, I. T. (1997) Sampling in qualitative research. Purposeful and theoretical sampling; merging or clear boundaries. Journal of Advanced Nursing, 26, 623 - 630. doi: 10.1046/j.1365-2648.1997.t01-2500999.x

Cranton, P. (1994). Understanding and promoting transformative learning: A guide for educators of adults. San Francisco, CA: Joss ey-Bass

Cranton, P. (1996). Professional development as transformative learning: New perspectives for teachers ofadults. San Francisco, CA: Jos sey-Bass.

Creswell, J. W. (2013). Qualitative inquiry and research design. Los Angeles, CA: Sage Publications, Inc.

Creswell, J. W., \& Plano Clark, V.L. (2011). Designing and conduction mixed methods research, (2nd ed.) Thous and Oaks, CA: Sage Publications, Inc.

Cross, T., Bazron, B. Dennis, K., \& Issacs, M. (1989). Towards a culturally competent system of care. Washington, D.C.: Georgetown University Child Development Center. 
Curry, L. A., Nembhard, I. M., \& Bradley, E. H. (2009). Key issues in outcome research: Qualitative and mixed methods provide unique contributions to outcomes research. American Heart Association. Retrieved from http://circ.ahajournals.org/content/119/10/1442.full \#cited-by. doi: 10.1161/circulationaha.107.742775

Darling-Hammond, L. (2006). Constructing 21stcentury teacher education. Journal of Teacher Education, (57)3, 300-314.

Darling-Hammond, L., \& Bransford, J. (2007). Preparing teachers for a changing world: What teachers should learn and be able to do. San Francisco, CA: John Wiley \& Sons.

Denzin, N. K. (1978). Sociological Methods. New York, NY: McGraw Hill.

Denzin, N., \& Lincoln, Y. (Eds.). (2005). Handbook of qualitativeresearch (3rd ed.). Thous and Oaks, CA: Sage.

Eriks on, E.H. (1959). Identity and the Life Cycle. Psychological Issues, 1, 22.

Erikson, E. H. (1963). Childhood and society (2nd ed.). New York, NY: Norton.

Gay, G. (2010). Culturallyresponsive teaching: Theory, research and practice(2nd ed.). New York, NY: Teachers College Press.

Grant, C., Elsbree, A.R., \& Fondrie, S. (2004). A decade of research on the changing terrain of multicultural education research. In J.A. Bands \& C.A.M. Bands (Eds.), Handbook ofresearchon multicultural education (2nd ed., pp. 184-207). San Francisco, CA: Jossey-Bass.

Grant, C., \& Sleeter, C. (1988). Making choices for multiculturaleducation: Five approaches to race, class, and gender. Columbus, $\mathrm{OH}$ : Merrill.

Grant, C., \& Sleeter, C. (2006). Turning on learning: Five approaches to multicultural teaching plans for race, class, gender, and disability (4th ed.). Upper Saddle River, NJ: Prentice-Hall.

Green, J. \& Thorogood, N. (2014). Qualitative Methods for Health Research. Los Angeles, CA: Sage Publications, Inc.

Howard, G. R. (1999). We can't teach what we don't know: White teachers, multiracial schools. New York, NY: Teachers College Press.

Hoy, A. W. \& Hoy, W. K. (2006). Instructional leadership: A researchbased guide to learning in schools. (2nd ed.). Boston, MA: Allyn and Bacon.

Imel, S. (1998). The balancing act of adult life. Transformativelearning in adulthood. ERIC Digest No. 200. Retrieved from: http://www.calproonline.org/Eric/docs/dig229.pdf

Kember, D., Leung, D. Y. P., Jones, A., Loke, A. Y., McKay, J., Sinclair, K., Tse, H., Webb, C., Wong, F. K. Y., Wong, M., \& Yeung, E. (2000). Development of a questionnaire to measure the level of reflective thinking. Assessment \& Evaluation in Higher Education, 25(4), 381-395.
King, K. P. (2005). Bringing transformative learning to life. Malabar, FL: Krieger Publishing Company.

Ladson-Billings, G. (2001). Crossing over to Canaan: The journey ofnew teachers in diverse classrooms. San Francisco, CA: Jossey-Bass.

Little, J.W.(1994). Teachers' professional development in a climate of education reform. Educational Evaluation and Policy Analysis, 15(2), 129-151. doi: 10.3102/01623737015002129

McCaslin, N., \& Parks, D. (2002). Teacher education in career and technical education: Background and policy implications for the new millennium. Journal of VocationalEducation Research, 27(1), 69-107.

Merriam, S. B. (1988). Case study research in education: A qualitative approach. San Francisco, CA: Jossey-Bass.

Mezirow, J. (1990). Fostering critical reflection in adulthood: A guide to transformative and emancipatory learning. San Francisco, CA: JosseyBass.

Mezirow, J. (1991). Transformative dimensions of adult leaning. San Francisco, CA: Jossey-Bass.

Mezirow, J. (1994). Understand transformative theory. Adult Education Quarterly, 44, 222-232.

Mezirow, J. (1995). Transformative theory of adult learning. In M.R. Welton (Ed.), Defense of the life world (pp. 39-70). New York, NY: SUNY Press.

Mezirow, J. (1996). Contemporary paradigms of learning. Adult Education Quarterly, 46, 158-172. doi:10.1177/074171369604600303

Mezirow, J. (2000). Learning as transformation. San Francisco, CA: Jossey-Bass.

Mezirow, J. (2009). An overview of transformative learning. In K. Illeris (Ed.), Contemporary theories oflearning (pp.90-105). New York, NY: Rutledge.

Milner, H. R. (2010). What does teacher education have to do with teaching? Implications for diversity studies. Journal of Teacher Education, 61(1-2), 118-131.

Nieto, S., \& Bode, P. (2008). Affirming diversity: The sociopolitical context of multiculturaleducation (5th ed.). Boston, MA: Allyn \& Bacon.

Nosek, B. A., Greenwald, A. G., \& Banaji, M.R. (2007). The implicit association test at age 7: A methodological and conceptual review. In J.A. Bargh (Ed.), Automatic process in social thinking and behavior (pp. 265-292). Oxford, United Kingdom: Psychology Press.

Patton, M. Q. (1990). Qualitative evaluation and research methods (2nd ed.). Newbury Park, CA: Sage.

Patton, M.Q. (1999). Enhancing the quality and credibility of qualitative analysis. HSR: Health Services Research, 34(5), 1189-1208.

Project Implicit. (2011). Project implicit research. Retrieved from http://www.projectimplicit.net/research.html 
Reese, S. (2005). An education in diversity. Techniques, 80(7), 14-17.

Rodgers, C. R. \& Scott, K. H. (2008). The development of the personal self and professional identity in learning to teach. In Cochran-Smith, FeimanNemser, McIntyre, \& Demers (Eds.) Handbook of Research on Teacher Education: Enduring Questions in Changing Contexts (pp. 732-755). New York, NY: Routledge.

Ruhland, S. K., \& Bremer, C. D. (2002). Alternative teacher certification procedures and professional developmentopportunities for career and technical education teachers (NDCCTE Report 143). Retrieved from http://files.eric.ed.gov/fulltext/ED472438.pdf

Sparks, D. (1999). Teachers must be at the core. Journal of StaffDevelopment, 20(4). Retrieved from http://www.nsdc.org/library/jsd/voices204.html

Spindler, G., \& Spindler, L. (1993). The process of culture and person: Cultural therapy and culturally diverse schools. In P. Phelan \& A. L. Davids on (Eds.), Renegotiating cultural diversityin American school (pp. 21-51). New York, NY: Teachers College.
Stone, J. (2010). Professional development for secondary career and technicaleducation: Implications for change (Grant No. VO51A070003). Retrieved from http://www.nrccte.org/sites/default/files/publication files/professional_development_joint_2010.pdf

Taylor, E.W. (1998). Transformative learning: A critical review. ERIC Clearinghouse on Adult, Career, \& Vocational Education(Information Series No. 374), Retrieved from http://files .eric.ed.gov/fulltext/ED423422.pdf

Taylor, E. W. (2007). An update of trans formative learning theory: A critical review of the empirical research (1999-2005). International Journal of Lifelong Education, 26(2), 173-191.

Vondracek, F.W., Schulenberg, J., Skorikov, V., Gillespie, L.K., \& Wahlheim, C. (1995). The relationship of identity status to career indecision during adolescence. JournalofAdolescence, 18, 17-29.

Zeichner, K., \& Liston, D. (1996). Reflective teaching: An introduction. Mahwah, NJ: Erlbaum Associates, Inc. 